\title{
The anticancer effect of Bioconverted Danggui Liuhuang Decoction EtOH extracts in human colorectal cancer cell lines
}

\author{
Hyo-Hyun Park ${ }^{1} \cdot$ Ji-Eun Park ${ }^{1} \cdot$ Eun-Kyung Son ${ }^{1} \cdot$ Bo-Mi Kim $^{1} \cdot$ Jai-Hyun So $^{1}$ if
}

Received: 2 December 2019 / Accepted: 11 March 2020 / Published Online: 31 March 2020

(C) The Korean Society for Applied Biological Chemistry 2020

\begin{abstract}
Objective: The objective of our study was to investigate anti-cancer effects of Danggui Liuhuang Decoction extract bioconverted by protease liquid coenzyme of Aspergillus kawachii (DLD-BE), compared to a non-bioconverted DLD extract (DLDE) and determine the underlying mechanisms. Methods: DLD-E and DLD-BE were evaluated for their ability to modulate these signaling pathways and suppress the proliferation of human colorectal cancer (CRC) cells, HCT-116, LoVo, and HT-29. The anti-cancer effects of DLD-E and DLD-BE were measured by using proliferation and migration assays, cell cycle analysis, Western blots, and real-time PCR. Results: In this study, treatment with DLD-E and DLD-BE at concentrations of $25-100 \mu \mathrm{g} / \mathrm{mL}$ inhibited proliferation and migration in human CRC cells. DLD-BE induced apoptotic cell death and decreased COX-2 expression in HT-29 cells. The mechanisms of action included modulation of the AKT and extracellular-signal-regulated kinase signaling cascades along with inhibition of COX-2 expression. The results demonstrate novel anti-cancer mechanisms of DLD-BE against the growth of human CRC cells. Thus, we propose that DLD-BE can be developed as a more potent supplement to inhibit colorectal tumor growth and intestinal inflammation than DLD-E.
\end{abstract}

Keywords Bioconverted extract of Danggui Liuhuang Decoction - Colorectal cancer - Cyclooxygenase-2 - Decoction extract . Extracellular-signal-regulated kinase $\cdot$ Liuhuang $\cdot$ Protein kinase B

Jai-Hyun So $(\triangle)$

E-mail: dukeny@hanmail.net

${ }^{1}$ Department of Korean Medicine Development, National Development Institute of Korean Medicine, Gyeongsan, Gyeongsangbuk-do 38540, Republic of Korea

This is an Open Access article distributed under the terms of the Creative Commons Attribution Non-Commercial License (http://creativecommons. org/licenses/by-nc/3.0/) which permits unrestricted non-commercial use, distribution, and reproduction in any medium, provided the original work is properly cited.

\section{Introduction}

Colorectal cancer (CRC) is one of the most common malignancies in humans, with a high incidence and rising mortality rates worldwide [1,2]. Along with loss or mutation in tumor suppressor genes, regulation of cell survival, cell proliferation, inflammation and angiogenesis also play important role in CRC development and progression $[3,4]$.

Cyclooxygenase (COX)-2, a key rate-limiting enzyme in the conversion of arachidonic acid to prostanoids, is undetectable or expressed at low levels in most normal tissue, but it is known to be overexpressed in inflammatory bowel disease (IBD) and most colorectal adenomas and adenocarcinomas [5-7].

COX-2 expression is regulated by intracellular signal transduction including mitogen-activated protein (MAP) kinase [8], and it is also associated with AKT signaling in colon cancer cells $[9,10]$. Inhibition of COX-2 expression with selective COX-2 inhibitors has been reported to effectively prevent proliferation, angiogenesis and inducement of apoptosis in human colon cancer cells [11,12]. However, many of these anticancer drugs such as selective COX2 inhibitors and nonsteroidal anti-inflammatory drugs have disadvantages either by having side effects or resistance of cancer to these chemotherapeutic drugs [13-15]. Thus, there has been a noticeable shift towards alternative therapeutic strategies using naturally available sources, recently. Many natural dietary phytochemicals present in fruits, vegetables and herb tea have been shown to be protective against cancer in vitro and in vivo.

Danggui Liuhuang Decoction (當歸六黃湯, DLD), a traditional Chinese medicine, known as Dangkwiyughwangtang (local name in korea), has been used as a treatment for fever, night sweats, red face, distress, dry mouth, and constipation. DLD consists of seven medicinal plants, i.e., Astragli Radix, Rehmanniae Radix preparata, Rehmanniae Radix, Angelicae Sinensis Radix, Scutellariae Radix, Coptidis Rhizoma, and Phellodendri Cortex [16,17].

Previous studies have reported that immunomodulatory effects of DLD in mice and anti-inflammatory effects in murine macrophage 
cell line. It has also been investigated that DLD can reverse premature ovarian failure. However, the effects of DLD on antitumor or anti- inflammation in human colorectal cancer cells and the mechanisms have not yet been investigated $[18,19]$.

Therefore, we aimed to evaluate the effects of non-bioconverted DLD extract (DLD-E) and bioconverted DLD extract (DLD-BE) on carcinogenesis of human cancer cells and determine the possible mechanisms of action. In the present study, we evaluated the effects of DLD-E and DLD-BE on cell survival, cell proliferation, migration and cell colony formation in human colon cancer cell lines, and confirmed whether DLD-BE inhibits the expression of proteins that induces apoptosis and inhibit survival of HCT-116 or HT-29 cells compared to DLD-E. In addition to, we confirmed that the effect of DLD-BE depends on AKT signaling that inhibit cell proliferation and COX-2 expression in HT-29.

\section{Materials and Methods}

\section{Preparation of Bioconverted Danggui Liuhuang Decoction}

Seven medicinal herbs, the components of Danggui Liuhuang Decoction (DLD) extracts were purchased from Oriental Medicine Market in Korea (Daegu) and was refluxed twice with $3.5 \mathrm{~L}$ of $70 \% \mathrm{MeOH}$ (a sample/MeOH ratio of 1:7 (w/w)). The extract was filtered through filter paper and concentrated using a Rotary evaporator (EYELA, Tokyo, Japan). The resulting extract was bioconverted using the enzyme isolated from the soybean paste fungi, Aspergillus kawachii (A. kawachii), according to a previous study with some modifications [20]. Briefly, extracts were resuspended in $200 \mathrm{~mL}$ of distilled water, and a $100 \mathrm{~mL}$ aliquot of the suspension was treated with $100 \mathrm{~mL}$ of active or inactive crude enzyme extract. The mixture was incubated with shaking at 100 $\mathrm{rpm}$ at $30{ }^{\circ} \mathrm{C}$. Inactive crude enzyme prepared by autoclaving the mixture at $121{ }^{\circ} \mathrm{C}$ for 15 min served as the control.

\section{Preparation of A. kawachii Enzyme}

The A. kawachii enzyme was prepared as previously described [20]. Briefly, A. kawachii grown in potato dextrose agar medium (Difco Laboratories, Detroit, MI, USA) was inoculated into sterilized wheat bran and incubated at $30{ }^{\circ} \mathrm{C}$ for 3 days. The resulting mixture was suspended in sodium phosphate buffer $(\mathrm{pH}$ 7.0) and incubated for $18 \mathrm{~h}$ at $4{ }^{\circ} \mathrm{C}$. The reaction mixture was then centrifuged, and the supernatant was used for fermentation of DLD extracts. The supernatant provided $0.276 \mathrm{U} / \mathrm{mL}(1 \mathrm{U}$ is defined as the enzyme activity needed to produce $1 \mathrm{mmol}$ of $\rho$ nitrobenzene from $\rho$-nitrophenyl- $\beta$-D-glucopyranoside per min) $\beta$ glucosidase activity [20].

\section{Materials and Cell Culture}

Human colon cancer cell line (HCT-116, HT-29) and rat normal intestinal cell line (IEC-6) were obtained from the Korean Cell
Line Bank (Seoul, Korea). RPMI 1640 medium, fetal bovine serum (FBS), and antibiotics (penicillin/streptomycin) were purchased from Hyclone (Logan, UT, USA). Antibodies specific for COX2 , TNF- $\alpha$, IL-1 $\beta$ and P-AKT were purchased from Cell Signaling (Beverly, MA, USA). Secondary antibodies (goat anti-rabbit and anti-mouse) were obtained from Santa Cruz Biotechnology (Santa Cruz, CA, USA). Cell viability was assessed using the CellTiter 96 Aqueous One Solution Assay kit (Promega, Madison, WI, USA) and primers for real time PCR were purchased from MBiotech Inc. (Hanam, Korea).

\section{Measurement of Cell Viability and Proliferation Assay}

Cells were cultured in RPMI 1640 medium supplemented with $10 \%$ FBS at $37{ }^{\circ} \mathrm{C}$ with humidified air containing $5 \% \mathrm{CO}_{2}$, and plated at a density of $1 \times 10^{6}$ cells $/ \mathrm{mL}$ in 96 -well plates for measurement of cell viability. The various concentrations of DLDE or DLD-BE were added, and the plates were incubated for $24 \mathrm{~h}$. The optical densities were measured at $490 \mathrm{~nm}$ using a microplate reader (Tecan System, San Jose, CA, USA) by MTS assay method. As a second method for determining the cytotoxicity of DLD-E or DLD-BE on cells we used the crystal violet assay. Upon solubilization, Cells $\left(5 \times 10^{5}\right)$ were seeded in 6 -well plates. They were incubated for $48 \mathrm{~h}$ with DLD-E or DLD-BE. After washing with phosphate-buffered saline (PBS) the cells were incubated and were slightly shaked at RT with staining solution ( $0.5 \%$ crystal violet, $20 \%$ methanol) which stains DNA. The plate was washed with $\mathrm{dH}_{2} \mathrm{O}$ and dried completely. Image were acquired using phase contrast microscope (Nikon, Tokyo, Japan, magnification $\times 100$ ). The uptaken crystal violet was solubilized by $30 \%$ acetic acid and the amount of dye was quantified by measuring the absorbance at $550 \mathrm{~nm}$ in a microplate reader.

\section{Measurement of Migration Assay}

Cells were also seeded in a 6-well plate, allowed to reach $90 \%$ confluence, and then they were scratched using a $1000 \mathrm{~mL}$ pipet tip. After washing with PBS, serum-free medium containing DLD-E or DLD-BE were added to the cells, followed by $48 \mathrm{~h}$ incubation. The scratches were monitored, and images were acquired using a phase contrast microscope (Nikon, Tokyo, Japan)

\section{Cell cycle and apoptosis analyses}

HT-29 cells at $5 \times 10^{5}$ cell/well were grown in a 6-well plate with different concentrations (50 and $100 \mu \mathrm{g} / \mathrm{mL}$ ) of DLD-E or DLDBE. Cells were harvested, washed with cold PBS, trypsinized, and centrifuged. Cells were suspended in $50 \mu \mathrm{L}$ cold PBS, $450 \mu \mathrm{L}$ of cold ethanol was added, and incubated at $4{ }^{\circ} \mathrm{C}$ for $1 \mathrm{~h}$. After centrifugation at $1000 \mathrm{rpm}$ for $5 \mathrm{~min}$, the pellet was washed with cold PBS, resuspended in $500 \mu \mathrm{L}$ PBS, and then incubated with $5 \mu \mathrm{L}$ RNase $\left(20 \mu \mathrm{g} / \mathrm{mL}\right.$ final concentration) at $37^{\circ} \mathrm{C}$ for $30 \mathrm{~min}$. The cells were chilled on ice for $10 \mathrm{~min}$ and incubated with propidium iodide at a final concentration of $50 \mu \mathrm{g} / \mathrm{mL}$ for $1 \mathrm{~h}$ in the dark. Cell cycle distribution was determined by flow cytometry, 
and DNA histograms for cell cycle analysis were determined using the FlowJo software (Tree Star, San Jose, CA, USA).

\section{RNA extraction and real time (RT)-PCR}

Total RNA was isolated from HT-29 cells using TRI Solution ${ }^{\text {TM }}$ according to the manufacturer's instructions (BSK Bioscience, Gyeongbuk, Korea). cDNA was synthesized from $1 \mu \mathrm{g}$ of total RNA using OligodT15 and Goscript ${ }^{\mathrm{TM}}$ Reverse transcription system kit (Promega, Madison, WI, USA). For RT-PCR, the primers were purchased from M-Biotech Inc. (Daejeon, Korea). The RT-PCR reaction was carried out on the StepOne Plus ${ }^{\mathrm{TM}}$ (Applied Biosystems, Foster City, CA, USA) using HotStart ${ }^{\circledR}$ SYBR $^{\circledR}$ Green qPCR Master Mix (USB, Cleveland, OH, USA). Each PCR cycle consisted of the 3 following steps: $95^{\circ} \mathrm{C}$ for 2 min, $95^{\circ} \mathrm{C}$ for $5 \mathrm{~s}, 60{ }^{\circ} \mathrm{C}$ for $30 \mathrm{~s}$. The results of RT-PCR were presented as pro-inflammatory cytokine gene (COX-2, TNF- $\alpha$, IL-1 $\beta$, IL-6) induction fold, and these were calculated using $\beta$ actin, which was amplified under the same conditions, as an internal control.

\section{Western blot analysis}

Cells $\left(1 \times 10^{6}\right.$ cells/well $)$ were treated with various concentrations of DLD-E or DLD-BE and incubated for $24 \mathrm{~h}$. For the total protein extract, cells were washed once with $10 \mathrm{mM}$ PBS (pH 7.4) containing $150 \mathrm{mM} \mathrm{NaCl}$ and then lysed with PRO-PREP ${ }^{\mathrm{TM}}$ Protein Extraction Solution (iNtRON Biotechnology, Daejeon, Korea) according to the manufacturer's protocol. Thirty micrograms of protein were applied to $10 \%$ SDS-polyacrylamide gels. The proteins were then transferred to nitrocellulose membranes in $20 \%$ methanol/25 mM Tris/192 mM glycine. Next, the membranes were blocked with $5 \%$ non-fat dry milk in TTBS (25 mM Tris$\mathrm{HCl}, 150 \mathrm{mM} \mathrm{NaCl}$, and $0.2 \%$ Tween-20) and then probed with various first antibodies. After $1 \mathrm{~h}$ of incubation followed by three washes, the membranes were incubated for $1 \mathrm{~h}$ with a secondary HRP-conjugated antibody. The protein bands were then visualized using an ECL system. The densities of the bands were measured with the ImageQuant LAS 4000 luminescent image analyzer and ImageQuant TL software system (GE Healthcare, Little Chalfont, UK). The GAPDH or total MAP kinase-normalized relative band intensity was presented.

\section{HPLC analysis}

The chromatographic system was composed of Agilent Technologies 1260 Infinity LC system coupled to SPD-M20A diode array detector. Detection and quantification were performed using Chemstation software. Each sample was analyzed on a Kinetex C18 column of $150 \mathrm{~mm} \times 4.6 \mathrm{~mm}, 2.6 \mu \mathrm{m}$ size (Phenomenex, Milford, CA, USA). The mobile phase consisted of water (A) and acetonitrile (B), which were applied in the gradient elution as follows: $20 \%$ Solvent B at $0 \mathrm{~min}, 20 \% \mathrm{~B}$ at $2 \mathrm{~min}, 80 \% \mathrm{~B}$ at 46 $\mathrm{min}$. The flow rate of the mobile phase was $1.0 \mathrm{~mL} / \mathrm{min}$, and the detection wavelength was $210 \mathrm{~nm}$. Calycosin and Wogonin were commercially available from Sigma and ChromaDex (Irvine, CA, USA).

\section{Statistical analysis}

The statistical analyses were performed using SPSS for Windows, version 18 (Chicago, IL, USA). Treatment effects were analyzed by one-way ANOVA, offered by Tukey's multiple range tests. ${ }^{*} p<0.05,{ }^{* *} p<0.01$ and ${ }^{* * *} p<0.001$ was considered statistically significant.

\section{Results and Discussion}

\section{DLD-BE significantly inhibited cell proliferation and migration and induced apoptosis in human CRC cells}

Apoptosis plays a pivotal role in controlling cell proliferation and migration, hence is significant to the prevention of cancer pathogenesis [21]. The Bcl-2 family proteins, including the antiapoptotic Bcl-2 members and pro-apoptotic Bax members, are the most characteristic regulators of mitochondria-mediated apoptosis. Bcl-2 conserves the integrity of the outer mitochondrial membrane and thereby, prevents the release of pro-apoptotic members from the mitochondria. The caspases play a critical role during apoptosis, particularly caspase- 3 . The activation of caspase- 3 is necessary for efficient apoptosis. Activated caspase-3 induces degradation of proteins, such as PARP, which are involved in the morphological features of apoptosis. When PARP is cleaved and inactivated by caspase-3, the cleaved PARP level is increased, indicating that the cell is undergoing apoptosis [22,23].

In the current study, the HT-29 colorectal cancer cells were treated with DLD extracts for $24 \mathrm{~h}$ before and after bioconversion and the effects on cell proliferation and migration were compared. The results showed that DLD-E and DLD-BE inhibited the proliferation of cancer cells in a dose-dependent manner compared to the control group that was not treated with DLD-E or DLD-BE and that DLD-BE was more effective than DLD-E. In addition, DLD-BE treatment induced a sub G1 phase suggestive of apoptotic cell death by stopping the progression from the G0 phase to the G1 phase of the cell cycle. DLD-E and DLD-BE treatment also had no effect on a normal intestine cell line.

Since intracellular signals are led to apoptosis by DLD-BE, it decreased the expression of Bcl-2 protein, which inhibited apoptosis and increased Bax protein expression compared to the control group. The expression of these molecules appears to increase the permeability of the mitochondrial membrane and increase the release of cytochrome c. The expression of cleaved caspase- 3 and cleaved PARP protein was also increased by the activation of caspase-3. The results confirmed that DLD-BE is involved in the inhibition of cell proliferation by inducing apoptotic signals in HT-29 cells. 
(A)

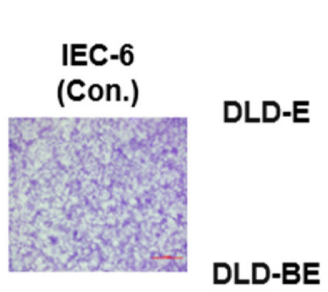

HCT-116

(Con.)

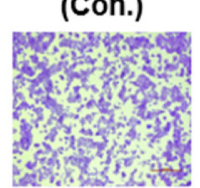

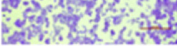

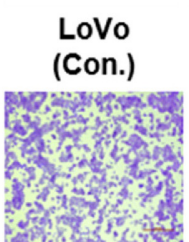

\section{DLD-BE}

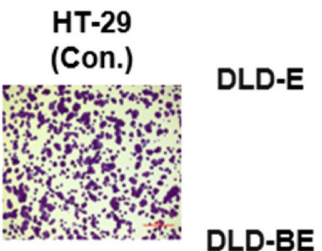

(C)

(0 h)

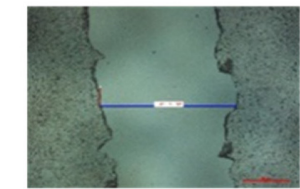

I

(48 h)

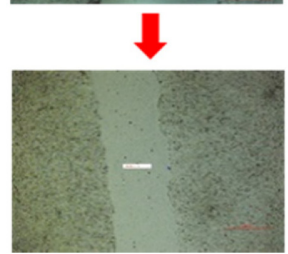

DLD-E

DLD-BE

DLD-E

DLD-BE
25

50

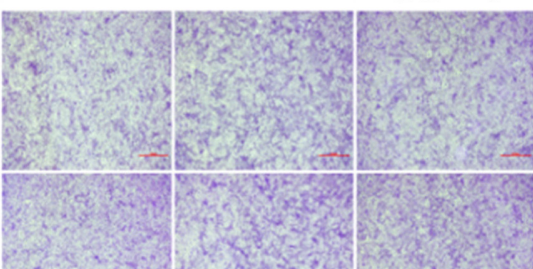

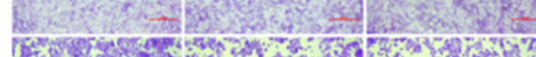
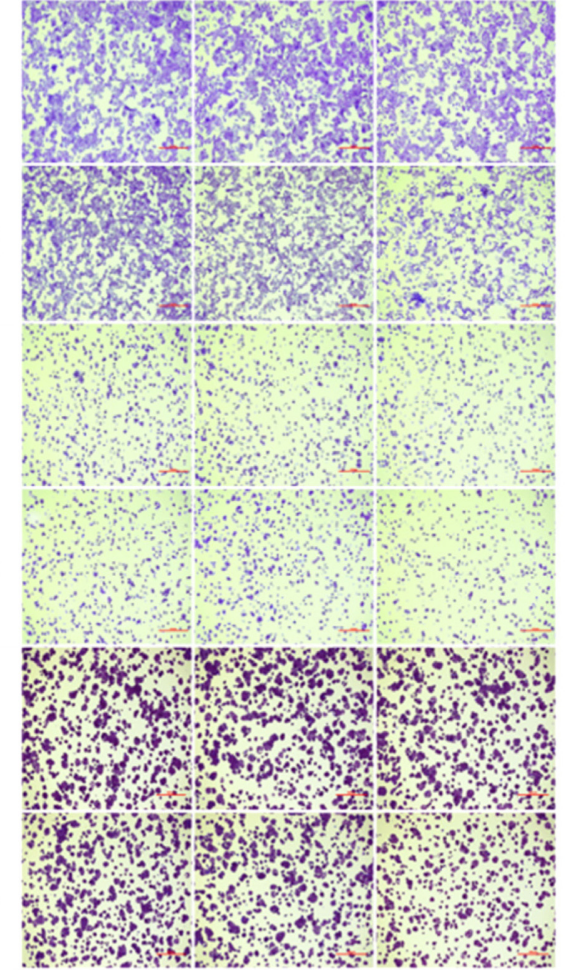

(B)
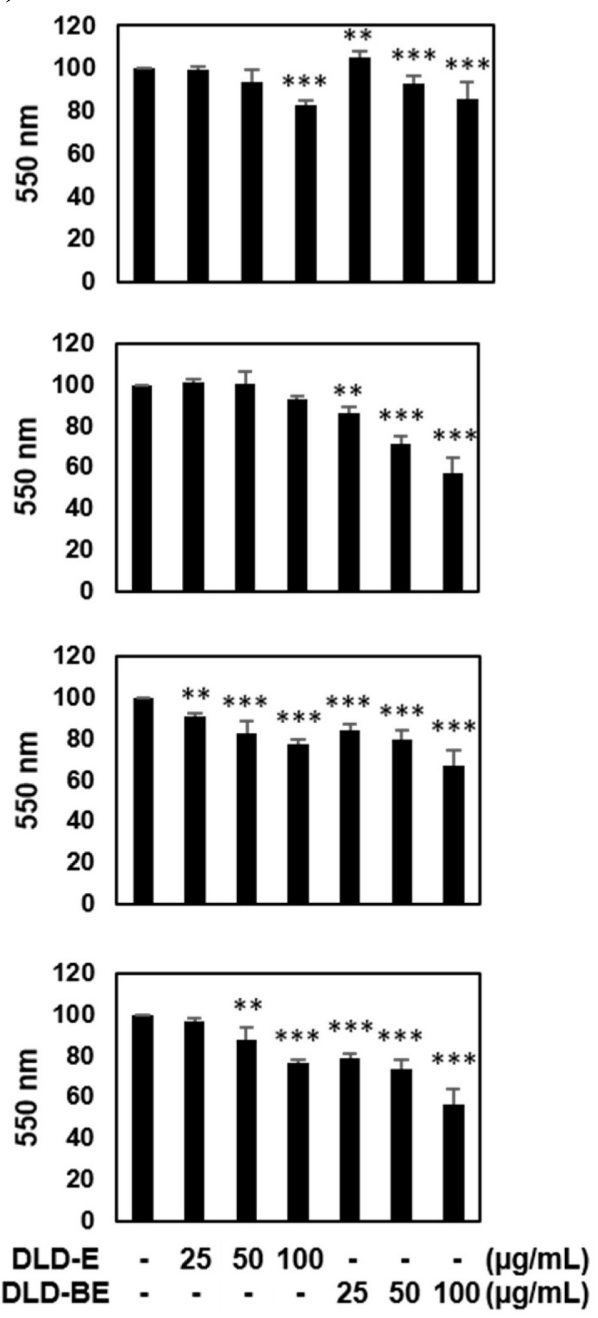

Fig. 1 Effect of non-bioconverted DLD extract (DLD-E) and bioconverted DLD extract (DLD-BE) on cell colony formation in colon cancer cells, compared to a normal intestinal cell line. Cells were stained with crystal violet, and then images were acquired using phase contrast microscope (A). Quantification of stained cell colonies was measured in $550 \mathrm{~nm}$ (B). Values are expressed as the means \pm standard deviation of three separate experiments. ${ }^{* *} p<0.05,{ }^{* * *} p<0.005$ vs. control. Cell migration was determined by the wound healing assay and the wounds were photographed at 0 and $48 \mathrm{~h}$ after creating the wound using an optical microscope (C). Original magnification (40X) 
(A)
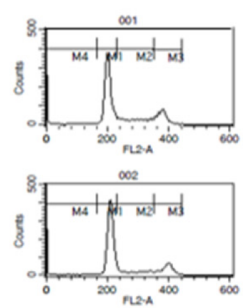

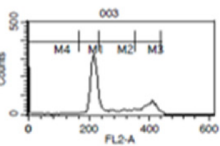

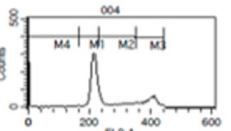

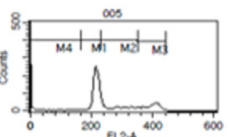

E0 phase $\quad$ G1 phase

=S phase $=\mathrm{G} 2 / \mathrm{M}$ phase

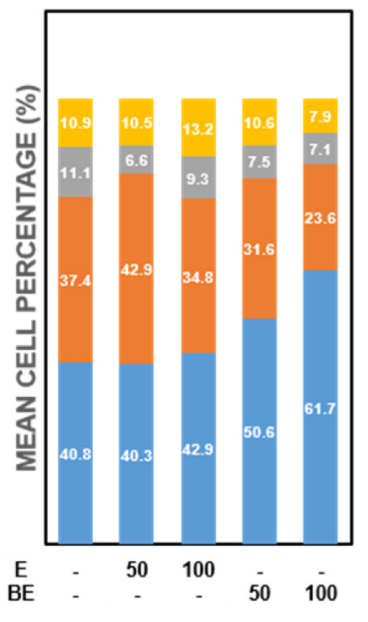

DLD $(\mu \mathrm{g} / \mathrm{mL})$
(B)

Capase-3

Cleaved Capase-3

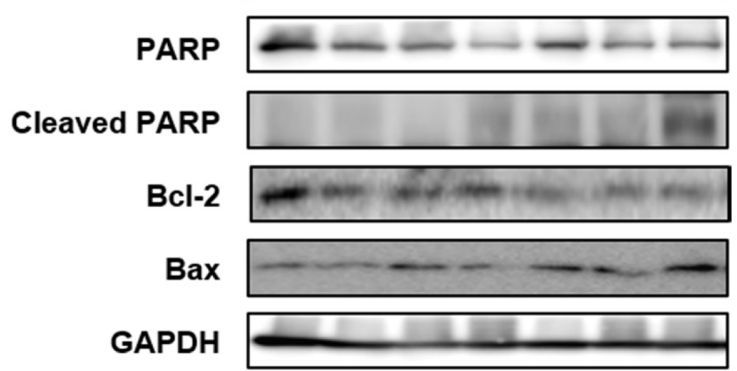

Cytochrom c $-\cdots$

GAPDH

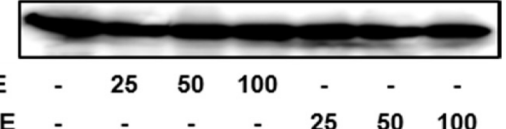

BE - - - $\quad-\quad \begin{array}{llll}25 & 50 & 100\end{array}$ DLD $(\mu \mathrm{g} / \mathrm{mL})$

Fig. 2 Effect of non-bioconverted DLD extract (DLD-E) and bioconverted DLD extract (DLD-BE) on cell death and alteration of various apoptotic protein expression of HT-29. Cells were treated with DYT-E and DYT-BE for $24 \mathrm{~h}$. (A) $\mathrm{G}_{0} / \mathrm{G}_{1}$ phase cells (\%) were determined using FACS analysis after staining for propidium iodide. (B) Expression levels of apoptotic protein in HT-29 were detected using western blot

(A)
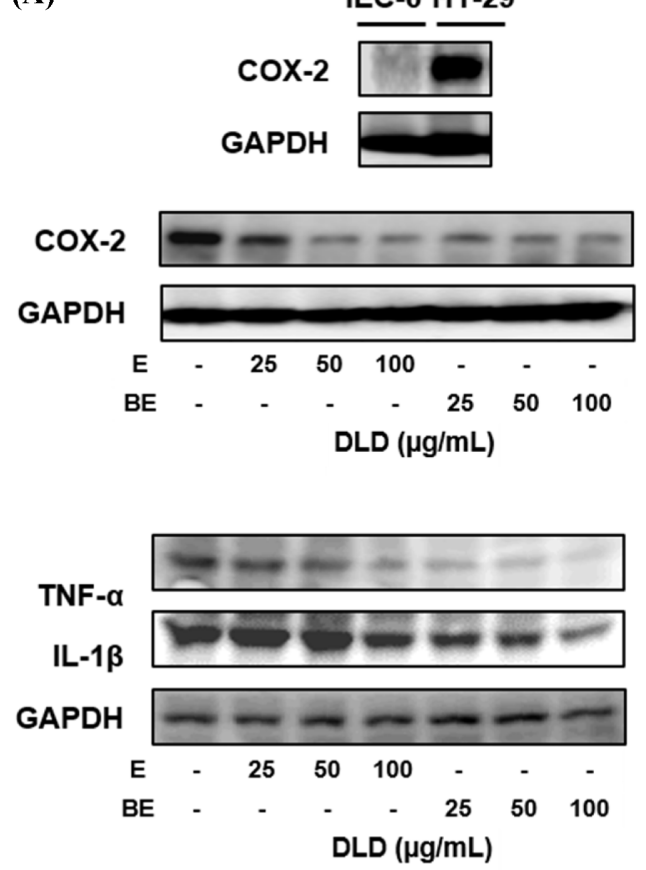

(B)
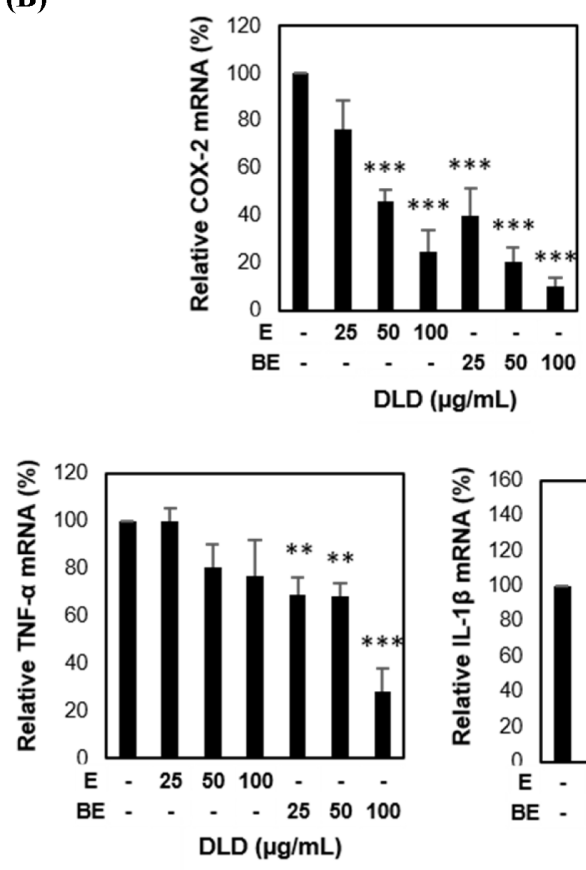

Fig. 3 Effect of non-bioconverted DLD extract (DLD-E) and bioconverted DLD extract (DLD-BE) on COX-2, TNF- $\alpha$ and IL-1 $\beta$ expression in HT-29, as determined by Western blot (A) and real time-PCR analysis (B). Values are expressed as the means \pm standard deviation of three separate experiments. ${ }^{*} p<0.5,{ }^{* *} p<0.05,{ }^{* * *} p<0.005$ vs. control

DLD-E and DLD-BE suppressed the expression of COX-2, TNF- $\alpha$, and IL-1 $\beta$ in HT-29 cells

COX-2 is rarely expressed in normal tissues, but is overexpressed in various cancers, including colorectal cancer, and has been reported to reduce the survival rate of colorectal cancer patients. It has been recognized as an important target for the prevention 
(A)
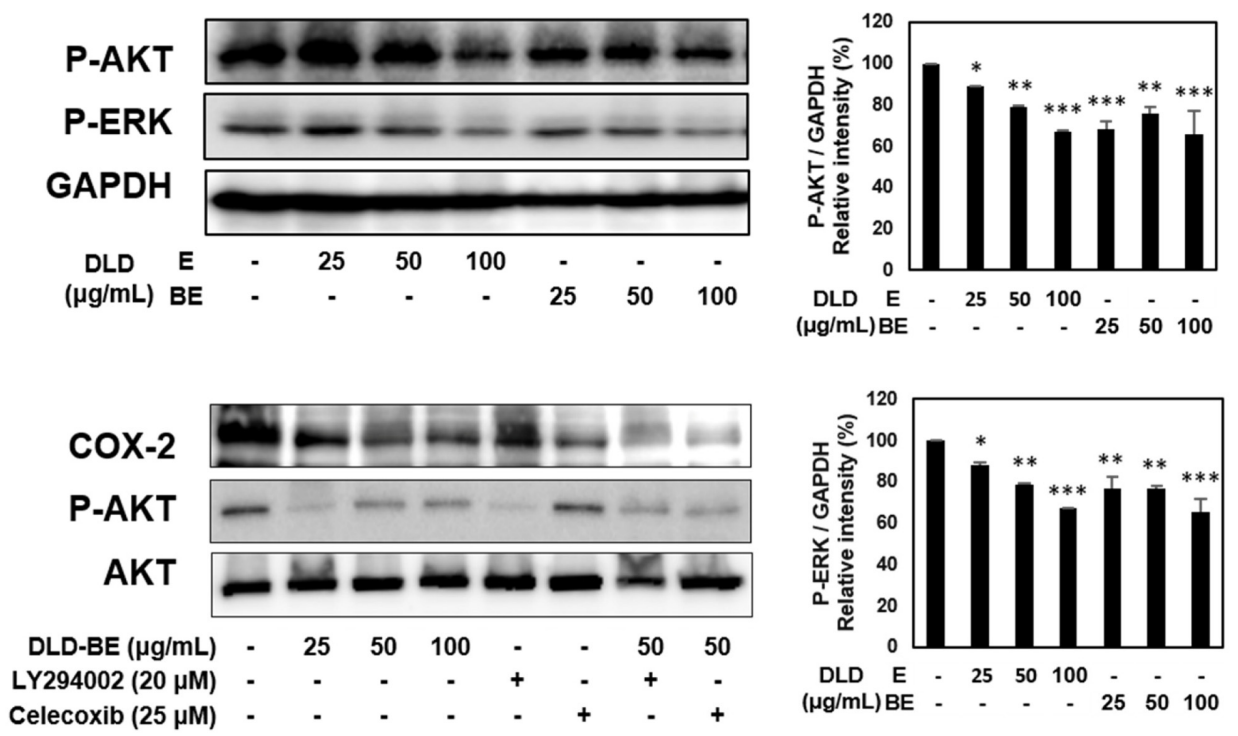

(B)

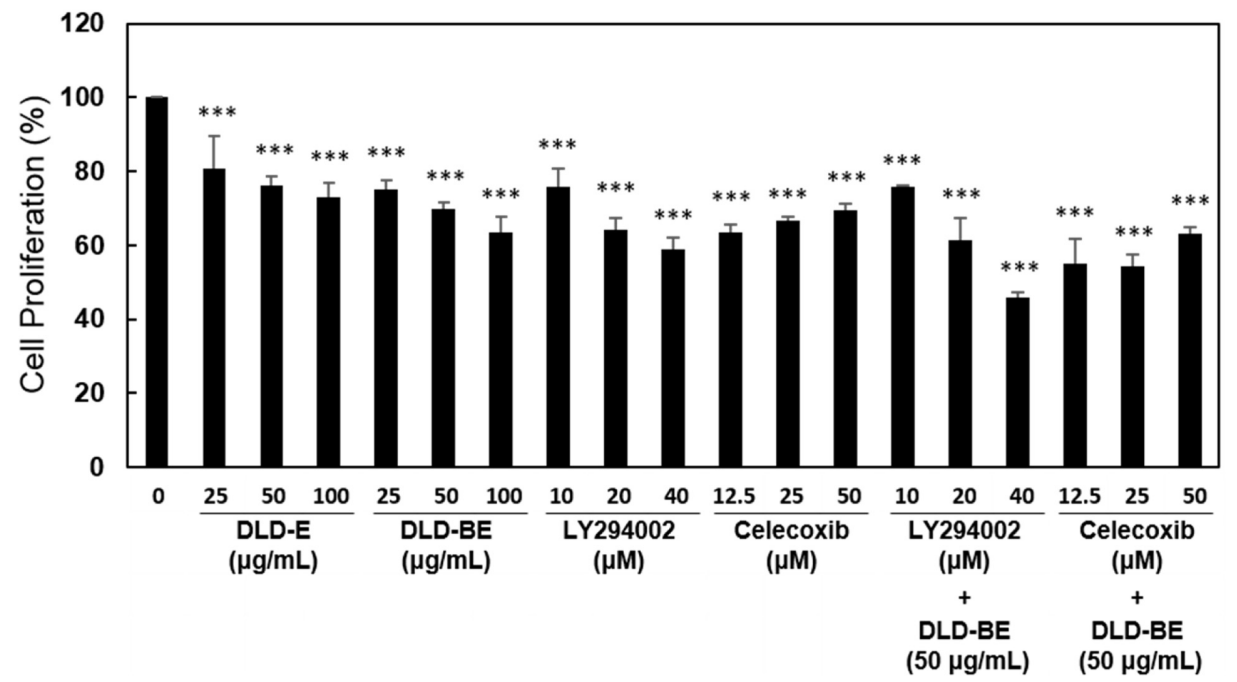

Fig. 4 Effect of non-bioconverted DLD extract (DLD-E) and bioconverted DLD extract (DLD-BE) on the phosphorylation of AKT and ERK in HT-29 cells, and change of COX-2 expression by inhibition of AKT pathway (A). Treatment with LY294002 (an AKT inhibitor) decreased cell proliferation of HT-29 cells, while a combined treatment with LY294002 and DYT-BE resulted in even further inhibits proliferation. Celecoxib, an effective nonsteroidal anti-iInflammatory drug was used to compare the activity of DYT-BE (B). ${ }^{*} p<0.5,{ }^{* *} p<0.05,{ }^{* * *} p<0.005$ vs. control

and treatment of colorectal cancer [4,7]. It is also associated with the overall mechanisms of cancer growth, such as tumorigenesis and development, inhibition of apoptosis, angiogenesis and metastasis, and the inflammatory response of pro-inflammatory cytokines, such as TNF- $\alpha$ and IL-1 $\beta$, that contribute to colorectal cancer [5-7].

In this study, COX-2 protein was constitutively expressed in HT29 cells, although not expressed in IEC- 6 cells. We showed that DLD-E and DLD-BE suppressed the over-expressed COX-2 protein and mRNA levels in HT-29 cells while reducing the protein and mRNA expression levels of TNF- $\alpha$ and IL-1 $\beta$. It was confirmed that DLD-BE was more effective than DLD-E.
COX-2 regulation and apoptosis induction by DLD-BE are mediated by the AKT pathway

Many studies have suggested that mutations in phosphatidylinositide 3-kinase (PI3-K)/Akt and mitogen-activated protein kinase (MAPK)/ERK molecules are commonly observed in various types of cancer. Suppression of the PI3-K/Akt and MAPK/ERK signaling pathways leads to the blockade of cell proliferation, demonstrating the importance of these signaling cascades in the control of both cell cycle progression and cell growth during cancer development $[24,25]$. Therefore, the Akt and MAPK/ERK mechanisms play dominant roles in determining the fate of tumor growth. Studies have reported that COX-2 is derived from 


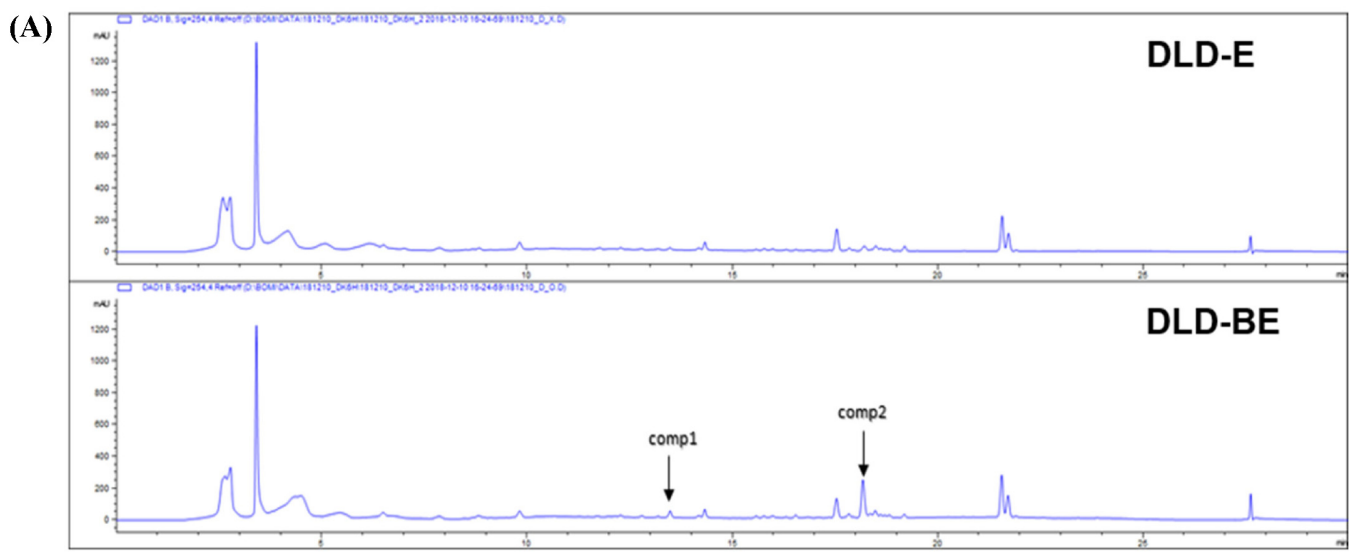

(B)

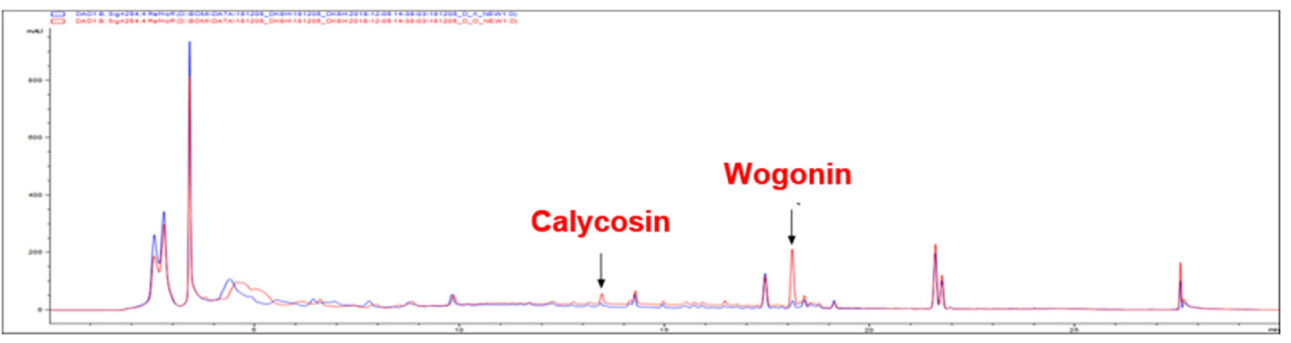

Fig. 5 Comparision of HPLC chromatogram of non-bioconverted DLD extract (DLD-E) and bioconverted DLD extract (DLD-BE). The HPLC results indicated that calycosin (compound 1) and wogonin (compound 2)

prostaglandins, particularly PGE2, and these signaling systems are associated with EGFR-PI3K-Akt, Ras-MAPK, PPAR, VEGF, Bcl-2, chemokines, canonical Wnt signaling systems, and the activation of these receptors [26-28].

Phytochemicals, such as selenium, curcumin, and EGCG, have been reported to inhibit the activation of Akt signaling, thereby inhibiting cancer cell proliferation, inducing apoptosis, and inhibiting tumor growth in vitro [29]. Therefore, regulation of the Akt pathways can play an important role in suppressing the abnormal proliferation of cancer cells.

In this study, we found that phosphorylation of AKT and ERK in HT-29 cells was inhibited by treatment with DLD-BE for $24 \mathrm{~h}$. In particular, the results showed that DLD-BE responded more specifically than DLD-E to inhibit the phosphorylation of AKT in the HT-29 cells. Cell proliferation was measured by treatment with LY294002, an AKT inhibitor or celecoxib, a COX-2 inhibitor, alone or in combination with DLD-BE for $24 \mathrm{~h}$. The results confirmed that cell proliferation was more strongly inhibited by combined treatment with LY294002 $(40 \mu \mathrm{M})$ and DLD-BE $(50 \mu \mathrm{g} / \mathrm{mL})$ or celecoxib $(25 \mu \mathrm{M})$ and DLD-BE $(50 \mu \mathrm{g} /$ $\mathrm{mL}$ ), compared to treatment with each agent alone.

Our findings suggest the potential of DLD-BE as a combination treatment or adjuvant anticancer agent for colorectal cancer that could have synergistic effects with existing anticancer drugs.

Bioconversion resulted in a significant change in compounds in the DLD extract

Bioconversion process is considered to be the key factor controlling the quality of herbal extracts and enhances the therapeutic effects of herbal medicine by changing the secondary metabolite composition and altering the mechanisms that are responsible for biological activity [30-32]. The production of a chemical compound that has pharmacological activity through bioconversion processes has great industrial interest due to its large scale production feasibility and environmental value as green chemistry.

In the present study, DLD-E and DLD-BE were analyzed by HPLC to evaluate changes occurring from the bioconversion of DLD. The HPLC analysis showed that components not seen in DLD-E were detected in DLD-BE. These components were identified as calycosin (compound 1) and wogonin (compound 2). Calycosin derived from the dry root extract of Radix Astragali is known to exhibit a variety of biological effects that easily undergo extensive phase II metabolism [33]. It is reported to stimulate the apoptosis of CRC cells and inhibit their invasion by acting as an SIRT1 activator, which induces the activation of AMPK-induced inhibition of the Akt/mTOR signaling pathway [34]. Wogonin is a plant monoflavonoid that has been reported to inhibit cell growth and/or induce apoptosis in various tumors and significantly induces apoptosis via the regulation of $\mathrm{Bcl}-2$ family proteins and activation of caspases in HT-29 cells [35]. These results suggest that bioconversion resulted in a significant change in compounds in the DLD extract.

In conclusion, we compared the anti-cancer efficacy and possible anti-cancer mechanisms of DLD-E and DLD-BE in HT29 human colorectal tumor cells. DLD-BE inhibited cell proliferation 
and migration and induced apoptosis by activating apoptosisinducing molecules in HT-29 cells. The mechanism involved inhibition of the AKT/ERK signaling pathways and the suppression of key markers of colon cancer development, such as COX-2, TNF- $\alpha$, and IL- $1 \beta$. Thus, we propose that the bioconverted extract of DLD using Aspergillus kawachii can be developed as a potent supplement to inhibit colorectal tumor growth and intestinal inflammation.

\section{References}

1. Siegel R, Ma J, Zou Z, Jemal A (2014) Cancer statistics, 2014. CA Cancer J Clin 64: 9-29

2. Siegel R, Desantis C, Jemal A (2014) Colorectal cancer statistics, 2014. CA Cancer J Clin 64: 104-117

3. Sano H, Kawahito Y, Wilder RL, Hashiramoto A, Mukai S, Asai K, Kimura S, Kato H, Kondo M, Hla T (1995) Expression of cyclooxygenase-1 and -2 in human colorectal cancer. Cancer Res 55: 3785-3789

4. Eberhart CE, Coffey RJ, Radhika A, Giardiello FM, Ferrenbach S, DuBois RN (1994) Up-regulation of cyclooxygenase 2 gene expression in human colorectal adenomas and adeno carcinomas. Gastroenterology 107: $1183-1188$

5. Singer II, Kawka DW, Schloemann S, Tessner T, Riehl T, Stenson WF (1998) Cyclooxygenase 2 is induced in colonic epithelial cells in inflammatory bowel disease. Gastroenterology 115: 297-306

6. Hendel J, Nielsen OH (1997) Expression of cyclooxygenase-2 mRNA in active inflammatory bowel disease. Am J Gastroenterol 92: 1170-1173

7. Eberhart CE, Coffey RJ, Radhika A, Giardiello FM, Ferrenbach S, DuBois RN (1994) Up-regulation of cyclooxygenase-2 gene expression in human colorectal adenomas and adenocarcinomas. Gastroenterology 107: 1183-1188

8. Niiro H, Otsuka T, Ogami E, Yamaoka K, Nagano S, Akahoshi M, Nakashima H, Arinobu Y, Izuhara K, Niho Y (1998) MAP kinase pathways as a route for regulatory mechanisms of IL-10 and IL-4 which inhibit COX-2 expression in human monocytes. Biochem Biophys Res Commun 250: 200-205

9. Phillips WA, Clair FS, Munday AD, Thomas RJS, Mitchell CA (1998) Increased levels of phosphatidylinositol 3-kinase activity in colorectal tumors. Cancer 83: 41-47

10. Sasaki T, Ine-Sasaki J, Hone J, Bachmeier K, Fata JE, Li M, Su A. (2000) Colorectal carcinomas in mice lacking the catalytic subunit of PI(3)Kgamma. Nature 406: 897-902

11. Mazhar D, Ang R, Wazman J (2006) COX inhibitors and breast cancer. Br J Cancer 94: 346-350

12. Das D, Arber N, Jankowski JA (2007) Chemoprevention of colorectal cancer. Digestion 76: 51-67

13. Silverstein FE, Faich G, Goldstein JL, Simon LS, Pincus T, Whelton A, Makuch R, Eisen G, Agrawal NM, Stenson WF, Burr AM, Zhao WW, Kent JD, Lefkowith JB, Verburg KM, Geis GS (2000) Gastrointestinal toxicity with celecoxib vs nonsteroidal anti-inflammatory drugs for osteoarthritis and rheumatoid arthritis: the CLASS study: a randomized controlled trial. Celecoxib Long-term Arthritis Safety Study. J Am Med Am 284: 1247-1255

14. Lisse JR, Perlman M, Johansson G, Shoemaker JR, Schechtman J, Skalky CS, Dixon ME, Polis AB, Mollen AJ, Geba GP; ADVANTAGE Study Group (2003) Gastrointestinal tolerability and effectiveness of rofecoxib versus naproxen in the treatment of osteoarthritis: a randomized, controlled trial. Ann Intern Med 139: 539-546

15. Bombardier C, Laine L, Reicin A, Shapiro D, Burgos-Vargas R, Davis
B, Day R, Ferraz MB, Hawkey CJ, Hochberg MC, Kvien TK, Schnitzer TJ; VIGOR Study Group (2000) Comparison of upper gastrointestinal toxicity of rofecoxib and naproxen in patients with rheumatoid arthritis. N Engl J Med 343: 1520-1528

16. Hur J (2005; Originally published in 1610) Dongui Bogam. Yeogang Publishing Company, Seoul

17. Li DY. Lan Shi Mi Cang (2012; Originally published in 1276) China Tianjin Science and Technology Press, Tianjin

18. Kim DG, Kim KS (2007) Effects of dangkwiyughwangtang and okbyoungpoongsangamibang on the immune response induced by methotrexate in mice. J Korean Orient Pediatr 21: 189-209

19. Kim SB, Kang OH, Keum JH, Mun SH, Seo YS, Choi JG, Kim MR, Rho JR, Shin DW, Kil KJ, Kwon DY (2012) Anti-inflammatory effects of Danggui Liuhuang Decoction () in RAW 264.7 cells. Chin J Integr Med 1-7

20. Yang EJ, Kim SI, Park SY, Bang HY, Jeong JH, So JH, Rhee IK, Song KS (2012) Fermentation enhances the in vitro antioxidative effect of onion (Allium Cepa) via an increase in quercetin content. Food Chem Toxicol 50: 2042-2048

21. Vyas S, Zaganjor E, Haigis MC (2016) Mitochondria and Cancer. Cell 166: 555-566

22. Del Bufalo D, Biroccio A, Leonetti C, Zupi G (1997) Bcl-2 overexpression enhances the metastatic potential of a human breast cancer line. FASEB J 11: 947-953

23. Pinkas J, Martin SS, Leder P (2004) Bcl-2-mediated cell survival promotes metastasis of EpH4 betaMEKDD mammary epithelial cells. Mol Cancer Res 2: 551-556

24. Halilovic E, She QB, Ye Q, Pagliarini R, Sellers WR, Solit DB, Rosen N (2010) PIK3CA mutation uncouples tumor growth and cyclin D1 regulation from MEK/ERK and mutant KRAS signaling. Cancer Res 70: 6804-6814

25. Wolter F, Akoglu B, Clausnitzer A, Stein J (2001) Downregulation of the cyclin D1/Cdk4 complex occurs during resveratrol-induced cell cycle arrest in colon cancer cell lines. J Nutr 131: 2197-2203

26. Kelloff GJ, Fay JR, Steele VE, Lubet RA, Boone CW, Crowell JA, Sigman CC (1996) Epidermal growth factor receptor tyrosine kinase inhibitors as potential cancer chemopreventives. Cancer Epidemiol Biomarkers Prev 5: 657-666

27. Wang D, Dubois RN (2008) Peroxisome proliferator-activated receptors and progression of colorectal cancer. Am J Respir Cell Mol Biol 39: 689-696

28. Wang D, Dubois RN (2006) Prostaglandins and cancer. Gut 55: 115-122

29. Robert T, Elizabeth B, Fabio M, Madeine W (2015) Phytochemicals in cancer prevention and management? BJMP 8: a815

30. Lee SG, Kim JS, Lee HS, Lim YM, So JH, Hahn D, Ha YS, Nam JO (2017) Bioconverted Orostachys japonicas extracts suppress angiogenic activity of Ms-1 endothelial cells. Int J Mol Sci 18: 2615

31. Jung TD, Shin GH, Kim JM, Oh JW, Choi SI, Lee JH, Cho ML, Lee SJ, Heo IJ, Park SJ (2016) Changes in Lignan Content and Antioxidant Activity of Fermented Sesame (Sesame indicum L.) by Cultivars. J Korean Soc Food Sci Nutr 45: 143-148

32. Im AR, Song JH, Lee MY, Yeon SH, Um KA, Chae S (2014) Antiwrinkle effects of fermented and non-fermented Cyclopia Intermedia in hairless mice. BMC Complement. Altern Med 14: 424

33. Gao J1, Liu ZJ, Chen T, Zhao D (2014) Pharmaceutical properties of calycosin, the major bioactive isoflavonoid in the dry root extract of Radix astragali. Pharm Biol. 52(9): 1217-1222

34. El-Kott AF, Al-Kahtani MA, Shati AA (2019) Calycosin induces apoptosis in adenocarcinoma HT29 cells by inducing cytotoxic autophagy mediated by SIRT1/AMPK-induced inhibition of Akt/mTOR. Clin Exp Pharmacol Physiol. 46: 944-954

35. Kim SJ, Kim HJ, Kim HR, Lee SH, Cho SD, Choi CS, Nam JS, Jung JY (2012) Antitumor actions of baicalein and wogonin in HT-29 human colorectal cancer cells. Mol Med Rep. 6: 1443-1449 